US Army Corps

of Engineers $s_{\circledast}$

Engineer Research and

Development Center

Microbiome Perturbations During Domestication of the Green June Beetle (Cotinis nitida)

Carina M. Jung, Matthew Carr, Denise L. Lindsay,

February 2022

Eric Fleischman, and Chandler J. Roesch 
The US Army Engineer Research and Development Center (ERDC) solves the nation's toughest engineering and environmental challenges. ERDC develops innovative solutions in civiland military engineering, geospatial sciences, water resources, and environmental sciences for the Army, the Department of Defense, civilian agencies, and our nation's publicgood. Find out more atwww.erdc.usace.army.mil.

To search for other technical reports published by ERDC, visit the ERDC online library at https://erdclibrary.on.worldcat.org/discovery. 


\section{Microbiome Perturbations During Domestica- tion of the Green June Beetle (Cotinis nitida)}

Carina M. Jung, Matthew Carr, Denise L. Lindsay,

Eric Fleischman, and Chandler J. Roesch

Environmental Laboratory

US Army Engineer Research and Development Center

3909 Halls Ferry Road

Vicksburg, MS 39180-6199

Final report

Approved for public release; distribution is unlimited.

Prepared for US Army Corps of Engineers

Washington, DC 20314-1000

Under Program Element 611102AB2, Project 484234, Task Number A1170 


\section{Abstract}

Animal-associated microbiomes are critical to the well-being and proper functioning of the animal host, but only limited studies have examined insect microbiomes across different developmental stages. These studies revealed large shifts in microbiome communities, often because of significant shifts in diet during insects' life cycle. Establishing insect colonies as model laboratory organisms and understanding how to properly feed and care for animals with complex and dynamic life cycles requires improved data. This study examined laboratory-raised green June beetles (Cotinis nitida) captured from the field upon emergence from pupae. Starting with wild-caught adults, two generations of beetles were reared in the laboratory, ending with an entirely laboratory-raised generation of larvae. The study compared the microbiomes of each generation and the microbiomes of larvae to adults. This study suggests that a diet of commercial, washed fruit for adults and commercial, packaged, organic alfalfa meal for larvae resulted in depauperate gut microbiome communities. Fermentative yeasts were completely absent in the laboratory-raised adults, and major bacterial population shifts occurred from one generation to the next, coupled with high morbidity and mortality in the laboratoryraised generation. Providing laboratory-raised beetles fresh-collected fruit and the larvae field-harvested detritus may therefore vastly improve their health and survival.

DISCLAIMER: The contents of this report are not to be used for advertising, publication, or promotional purposes. Citation of trade names does not constitute an official endorsement or approval of the use of such commercial products. All product names and trademarks cited are the property of their respective owners. The findings of this report are not to be construed as an official Department of the Army position unless so designated by other authorized documents. 


\section{Contents}

Abstract............................................................................................................. if

Figures and Tables......................................................................................... iv

Preface.....................................................................................................

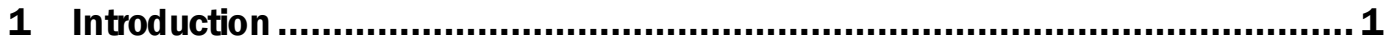

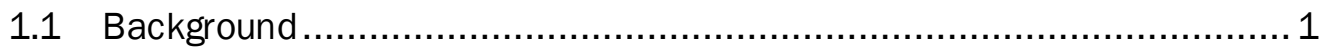

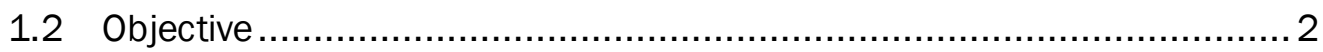

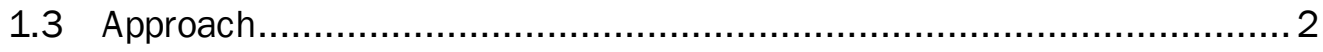

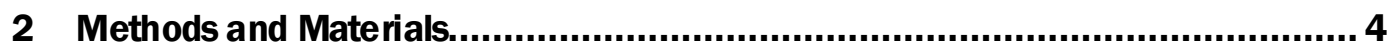

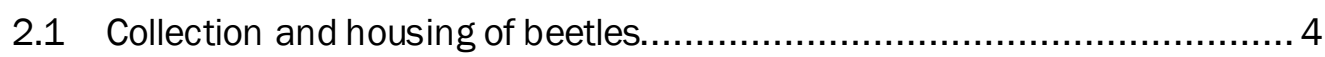

2.2 Gut microbiome analysis ........................................................... 7

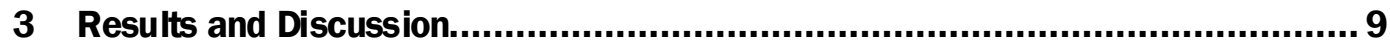

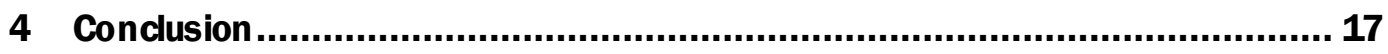

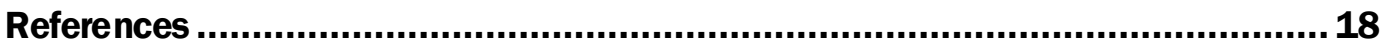




\section{Figures and Tables}

\section{Figures}

Figure 1. (A) Adult green June beetle (GJB) captured at (B) the University of Arkansas Agricultural Experiment Station using (C) modified vane traps.

Figure 2. (A) GJB adult rearing chamber with (B) beetles crawling on the flightspace screening.

Figure 3. (A) GJB eggs, and (B) collection with a small paint brush. The red circles indicate eggs.

Figure 4. Second instar larvae at 38 days. The red arrow $($ at $2.3 \mathrm{~cm})$ indicated the point at which the abdomen was liberated from the thorax.

Figure 5. Body weight (solid lines) and survival (dashed lines) of larvae from wildcaught (2018, open symbols) and laboratory-raised (2019, solid symbols) adult beetles.

Figure 6. Phylogenetic survey at the family level of soil, adult and larvae gut microbiomes. The Enterococcaceae are denoted by the dark rose bars with italicized data labels and the Pseudomonadaceae by the dark green bars with underlined data labels...

Figure 7. Averaged phylogenetic survey at the family level of adult and larvae gut microbiomes. The Porphyromonadaceae are denoted by the light blue bars with white data labels, the Pseudomonadaceae by the royal blue bars with italicized white data labels, the Lach nospiraceae by the maroon bars with italicized black data labels, and the Desulfovibrionaceae by the orange bars with underlined black data labels.

Figure 8. Alpha-diversity plot (PD Whole tree) of the averaged bacterial populations of each sample type.

Figure 9. Fungal internal transcribed spacer (ITS) phylogenetic survey at the Order level for soil, adult and larvae gut microbiomes from wild-caught beetles at the start of experimentation. Light blue bars with data labels belong to the Saccharomycetales.

\section{Tables}

Table 1. Egg and adultcounts for wild-caught beetles. ND = not determined. ............... 6

Table 2. Egg and adult counts for laboratory-raised beetles. ............................... 7

Table 3. Statistical summary of noteworthy population shifts from figure 7 using Kruskal-Wallis FDR $p$ values. 


\section{Preface}

This study was conducted for the US Army Engineer Research and Development Center (ERDC) Military Direct 6.1 Basic Research Program initiated in FY18, as Program Element 611102AB2, Project 484234, Task A1170.

The work was performed by the Environmental Processes Branch (EPP), Environmental Processes and Engineering Division (EPED), ERDCEnvironmental Laboratory (ERDC-EL). At the time of publication, Dr. Brandon Lafferty was Chief, EPP; Mr. Warren Lorentz was Chief, EPED; and Dr. Elizabeth Ferguson was the Technical Director for Environmental Quality and Installations, 6.1 Military Direct Program. The Deputy Director of ERDC-EL was Dr. Jack Davis and the Director was Dr. Edmond J. Russo.

COL Teresa Schlosser was the Commander of ERDC, and Dr. David Pittman was the ERDC Director.

Portions of this report and figures $2 \mathrm{~A}$ and 4 have been modified and reprinted from C. M. Jung, M. Carr, E. Fleischman, and C. J. Roesch, 2020, "Response of the Green June Beetle and Its Gut Microbiome to RDX and Phenanthrene," International Journal of Environmental Science and Technology (October), https://doi.org/10.1007/s13762-02002960-1. Public Domain. 


\section{Introduction}

\subsection{Background}

New invertebrate animal models are needed for toxicity, microbiome, behavioral, and ecological studies. Green June beetles (GJBs) (Cotinis nitida) are cosmopolitan pests that are unregulated by Animal and Plant Health Inspection Service-US Department of Agriculture (APHIS-USDA), easy to collect and handle, and they live most of their life as a soil-dwelling larvae, in intimate contact with the soil and rhizosophere. However, little information about rearing them in captivity exists, and in those few instances, they are reared in a greenhouse or external growth chamber-type environment (Johnson et al. 2009; Vishniac and Johnson 1990). In assessing the viability of this insect as an invertebrate model animal, livecaught adult GJBs were taken through an entire life cycle in a controlled laboratory environment. Their health, survival, reproduction, and gut microbiome were assessed.

Insect microbiomes have been studied sparingly, most notably in termites and, more recently, in honeybees. The dung beetle microbiome also has been a point of interest, given their unique diet of both liquid and solid mammalian fecal material. Studies have determined that the bacterial community of dung beetles shifts dramatically from larval to adult stages, starting with a maternal gift, which is an oral secretion upon which the mother places the egg within the brood ball (Shukla et al. 2016; Estes et al. 2013; Schwab et al. 2016). This gift is the first thing consumed by the larvae and contains a large bacterial inoculum, beneficial for the metabolism of the specialized diet of animal fecal material. The bacterial community profile becomes tailored to the diet of the developing larvae, which will contain larger plant polymers and higher $\mathrm{C}: \mathrm{N}^{1}$ ratios than the adult diet (Shukla et al. 2016). Understanding the microbiome of insects provides numerous advantages ranging from insect health to pest control. Colony collapse disorder of honeybees has been investigated most thoroughly, and there have been noted advantages to honeybees given probiotics or microbiome transplants with healthy honeybee microbiome inocula (Ptaszyńska

\footnotetext{
1. For a full list of the spelled-out forms of the chemical elements used in this document, please refer to US Government Publishing Office Style Manual, 31st ed. (Washington, DC: US Government Publishing Office, 2016), 265, https://www.govinfo.gov/content/pkg/GPO-STYLEMANUAL-2016/pdf/GPOSTYLEMANUAL-2016.pdf.
} 
et al. 2016). Biological control of pests through manipulation or perturbation of the host microbiome is a more socially palatable sidestep to chemical control or genetically modified organisms and one that may be gaining in application as next-generation sequencing reveals more information about a host's microbiome (Massart, Martinez-Medina, and Jijakli 2015).

Similar to other beetles, GJBs experience large dietary shifts in their different developmental stages. Adult GJBs eat simple sugars from softfleshed fruits, while the larvae forage among plant detritus, herbivore dung, microfungi, and inadvertently, soil and plant roots. The soil and plant root disruptions from both eating and tunneling have made the larvae (also called turf grubs) well-known major pests of golf courses and large turf areas (USEPA 2003). Although there is little research to date on the GJB microbiome (Vishniac and Johnson 1990), this shift in nutrient input should necessitate a parallel shift in the gut microbiome from large polymer degradation for larvae to simple carbon source metabolism for adults.

Adult GJBs are known to harbor fermentative yeasts in their gut microbiome (Vishniac and Johnson 1990), which develop upon emergence from the pupal stage. Previous work has shown that the culturable fraction of yeasts increases after emergence and appears to originate from feeding on yeast-laden fruit (Vishniac and Johnson 1990). Upon eating fermentable fruit, these yeasts increase, and fermentation is evident by the volatiles from defecation as well as defense and aggregation fecal spurt activity (D.T. Johnson et al. 2009; Vishniac and Johnson 1990).

\subsection{Objective}

As a means to more fully understand the development and dynamic nature of the GJB microbiome, a bacterial and fungal population survey was conducted via 16S rRNA and internal transcribed spacer (ITS) region highthroughput sequencing (Illumina MiSeq), respectively, in both the larval and adult life stages.

\subsection{Approach}

The current study was developed and executed as a survey on a small set of wild-caught, newly emerged green June beetles that were raised and bred in the laboratory. Their offspring were then fully reared to adulthood in the laboratory and allowed to breed an entirely captive-bred generation. 
The gut microbiome of each generation, and larvae and adult were then surveyed and compared by high throughput rRNA sequencing.

This report begins with an introduction to the green June Beetle and the importance of their gut microbiome. The collection and housing of the GJB are discussed along with molecular methods used to investigate the microbiomes. Finally, the results and discussion from study survey is presented with and overall study conclusions 


\section{Methods and Materials}

\subsection{Collection and housing of beetles}

GJB adults $(N=80)$ were trapped in agricultural fields at the University of Arkansas Agricultural Experiment Station in Fayetteville, Arkansas, using modified vane traps (D. Johnson 2009) (figure 1). Adults were transported to the US Army Engineer Research and Development Center (ERDC) in Vicksburg, Mississippi, and placed in a room with window access, maintained and retrofitted as a rearing facility. The beetles were placed in a 115 $\mathrm{L}$ food-grade plastic can filled to $0.3 \mathrm{~m}$ with mixed and $2 \mathrm{~mm}$ sieved soil substrate. ${ }^{2}$ The soil was comprised of local soil from ERDC believed to be free of pesticides or other contaminants; organic garden soil (Kellogg Garden Products, Carson, California); and sand (Pavestone Natural Play Sand, Atlanta, Georgia) in a 6:3:1 ratio. The rearing unit included a "flight space" made by inserting into the soil PVC pipes that extended $2 \mathrm{ft}$ beyond the opening and were covered with household door screening (figure 2). Adults were fed on a diversity of organic, store-bought mangoes, Pink Lady apples (with outer peel removed), and grapes.

Eggs were collected and quantified at least weekly by sieving soil through a $2 \mathrm{~mm}$ metal sieve and separating the eggs with fingers or a small paint brush (table 1; figure 3). Eggs were placed in a $3.8 \mathrm{~L}$ bucket containing $1 \mathrm{~L}$ of the same soil mixture used for adult rearing as well as a light dusting with organic alfalfa meal (Epsoma, Millville, New Jersey) added to the surface. Eggs were distributed throughout the soil by gently mixing. Summer room temperature $\left(\sim 25^{\circ} \mathrm{C}-28^{\circ} \mathrm{C}\right)$ with filtered natural light and a 12:12 light cycle were provided along with a daily spray of water to just wet the soil surface (Howe and Campbell 1953; D. Johnson 2009).

2. For a full list of the spelled-out forms of the units of measure used in this document, please refer to US Government Publishing Office Style Manual, 31st ed. (Washington, DC: US Government Publishing Office, 2016), 248-52, https://www.govinfo.gov/content/pkg/GPO-STYLEMANUAL-2016/pdf/GPOSTYLEMANUAL-2016.pdf. 
Figure 1. (A) Adult green June beetle (GJB) captured at (B) the University of Arkansas Agricultural Experiment Station using $(C)$ modified vane traps.
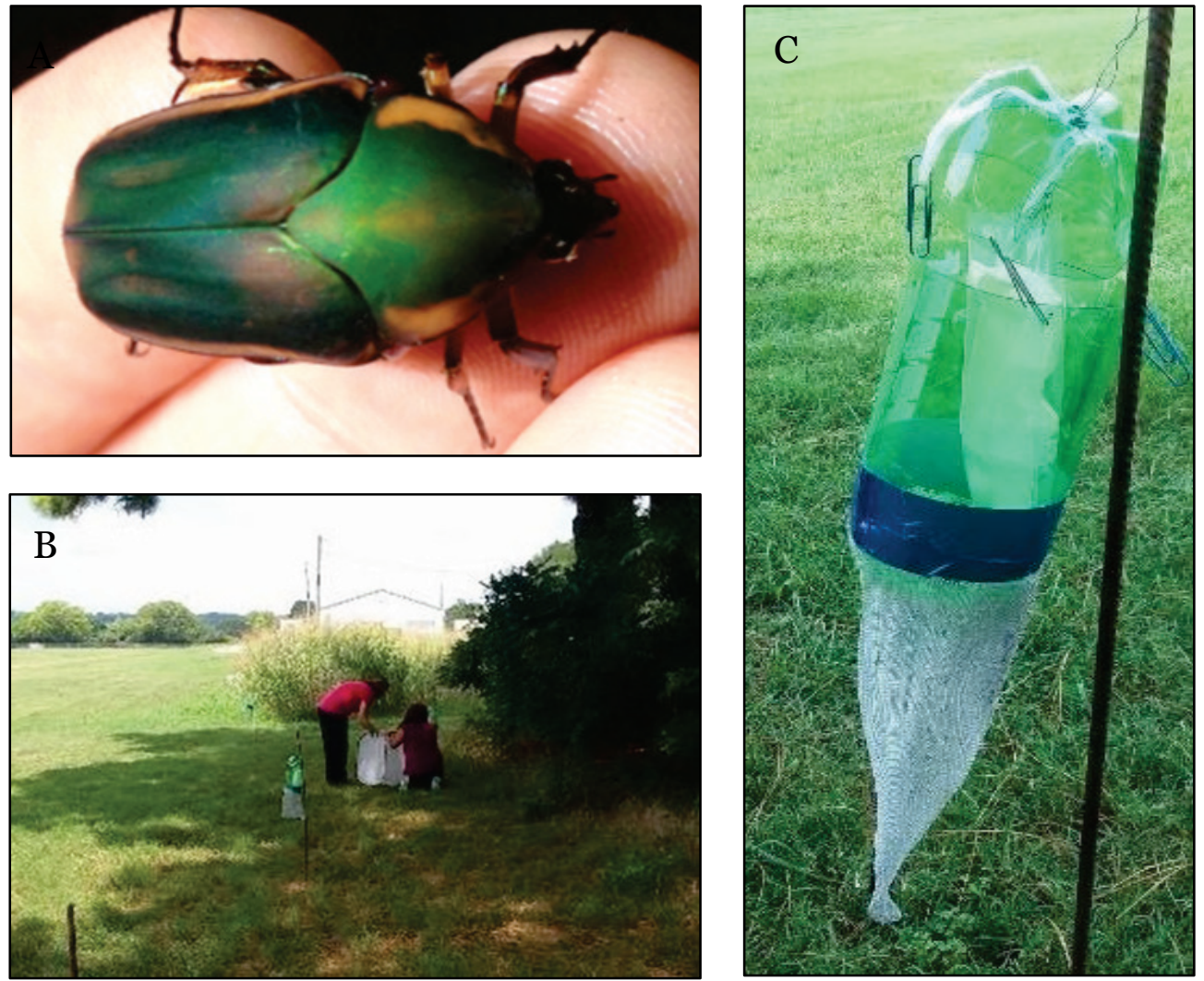

Figure 2. (A) GJB adult rearing chamber with (B) beetles crawling on the flight-space screening.
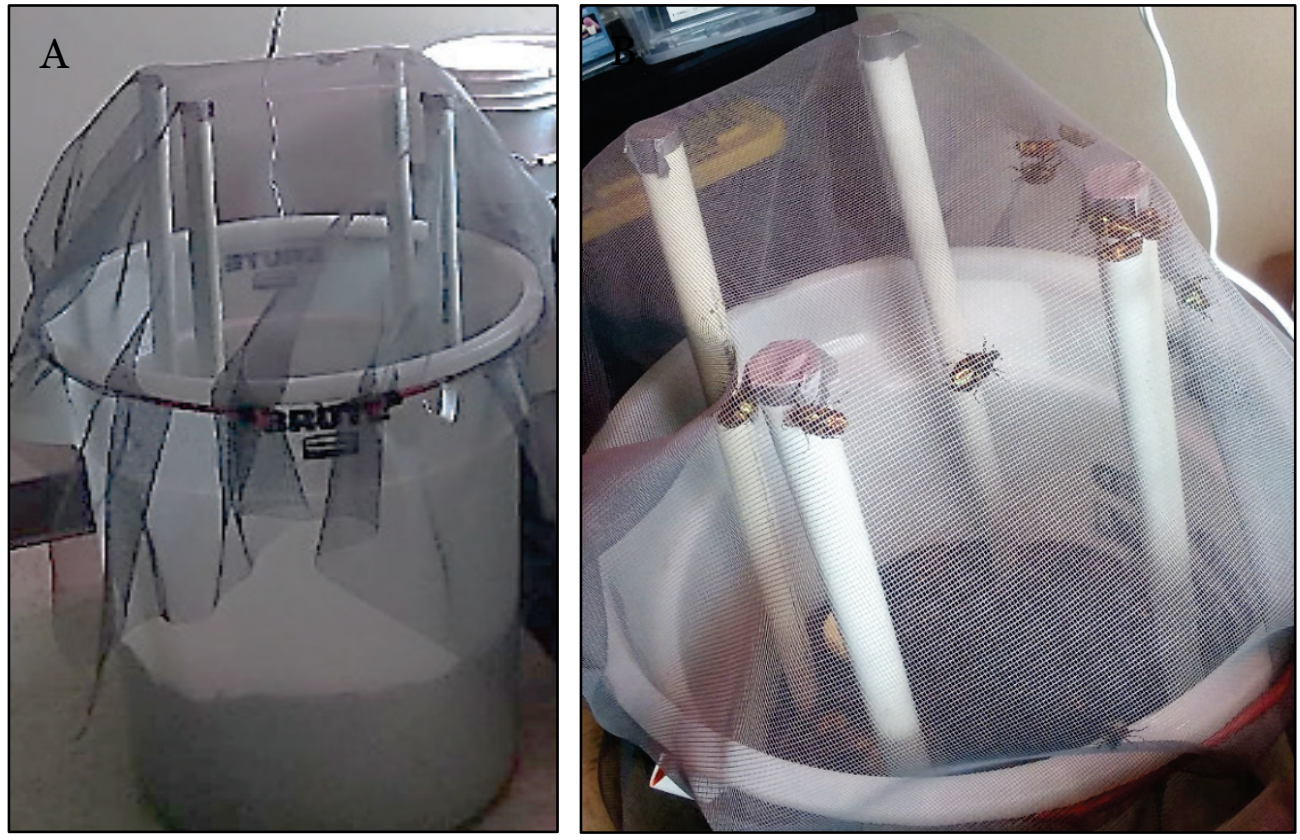
Table 1. Egg and adult counts for wild-caught beetles. ND = not determined.

\begin{tabular}{|lll|}
\hline Days postcapture & $\begin{array}{l}\text { \# of } \\
\text { eggs }\end{array}$ & $\begin{array}{l}\text { ad of } \\
0\end{array}$ \\
\hline 9 & 9 & 80 \\
13 & 30 & ND \\
16 & 353 & ND \\
19 & 98 & ND \\
26 & 286 & ND \\
33 & 370 & ND \\
37 & 235 & 39 \\
40 & 70 & ND \\
47 & 75 & ND \\
49 & 25 & 4 \\
\hline Total eggs & 0 & 0 \\
\hline
\end{tabular}

Figure 3. (A) GJB eggs, and (B) collection with a small paint brush. The red circles in dicate eggs.
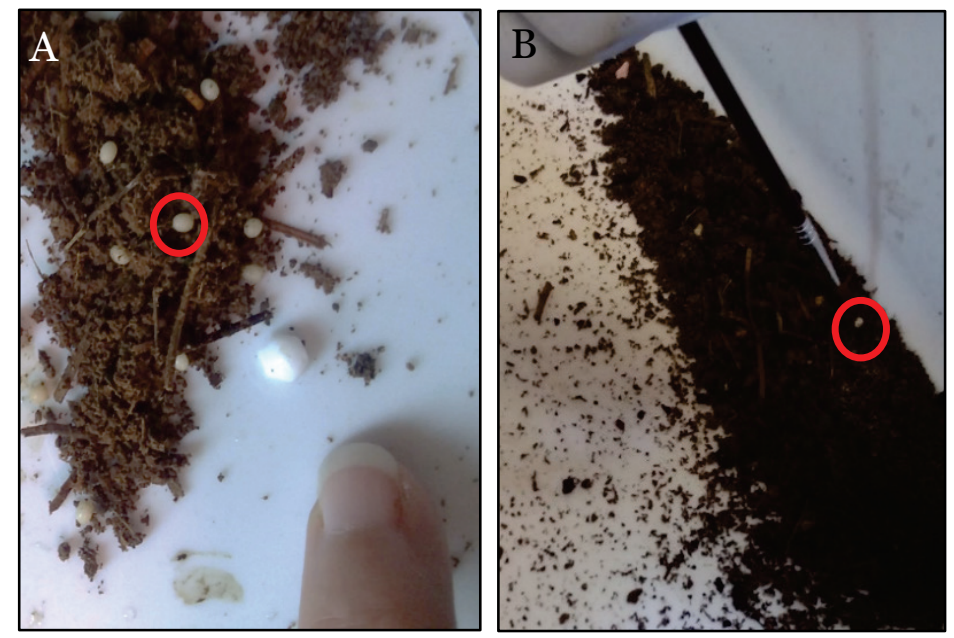

Larvae were collected after hatching (10-14 days) in the same manner as the eggs. Collected larvae were placed in a clear rectangular bin $(50 \times 43 \times$ $21.5 \mathrm{~cm}$ ) filled with $12.7 \mathrm{~cm}$ of the previously described soil mix topped with alfalfa meal. After one month the larvae were moved to new containers in groups of 50. Larvae containers were kept in a laboratory growth chamber set at $22^{\circ} \mathrm{C}, 75 \%$ humidity, a 12:12 light cycle, and an occasional spray of water when the soil surface appeared dry, and organic alfalfa meal 
was maintained on the soil surface. GJB need approximately 1000 freeze hours with reduced daylight during larval development (Donn Johnson, University of Arkansas, pers. comm.). In nature, larvae can modulate their environmental temperature and light exposure by moving vertically through the soil column. The laboratory setting, however, could not replicate this condition, as the soil temperature is relatively homogenous. It was recommended that the larvae be placed in a $4^{\circ} \mathrm{C}$ cooler for $1000 \mathrm{~h}(41$ days) starting at 16 weeks (Donn Johnson, University of Arkansas, pers. comm.). Within the $4^{\circ} \mathrm{C}$ chamber, a light:dark cycle of 8:16 was followed. After 41 days, temperature was increased weekly from $5^{\circ} \mathrm{C}$ to $17^{\circ} \mathrm{C}$ until multiple pupal balls were observed. The larvae and pupal balls were brought back to the GJB adult rearing chamber and placed in four separate 30 gal buckets with flight space to await their emergence as adults. Adults were captured and placed in a single rearing chamber, and eggs were harvested and quantified as before. Numbers of adults emerging from pupal balls and numbers of eggs collected are detailed in table 2.

Table 2. Egg and adult counts for laboratory-raised beetles.

\begin{tabular}{|cll|}
\hline $\begin{array}{c}\text { Weeks } \\
\text { postemergence }\end{array}$ & $\begin{array}{l}\text { \# of } \\
\text { eggs }\end{array}$ & $\begin{array}{l}\text { \# of } \\
\text { adults }\end{array}$ \\
\hline 1 & 262 & 23 \\
2 & 671 & 54 \\
3 & 517 & 46 \\
4 & 163 & 50 \\
5 & 240 & 10 \\
6 & 16 & 4 \\
7 & 4 & 0 \\
\hline Total eggs & 1873 \\
\hline
\end{tabular}

\subsection{Gut microbiome analysis}

Larvae $(n=5)$ at 3 (first instar) and 38 days (second instar) post-hatch were collected from the larval rearing chambers, frozen at $-20^{\circ} \mathrm{C}$ for $5 \mathrm{~min}$ to immobilize the larvae, and then surface sterilized in $95 \%$ ethanol for 5 min. The abdomen was liberated from the thorax (figure 4) using a sterile scalpel and the gut contents extruded and homogenized by vigorous vortexing. Adults were sampled randomly for feces by holding the end of their abdomen to a sterile microcentrifuge tube and lightly squeezing their ab- 
domen for fecal collection or by dissection and extrusion of the gut contents in the same manner as larvae. The DNA from the gut material was extracted, PCR amplified, and sequenced using an Illumina MiSeq platform (Illumina, San Diego, California) as described previously (J. G.

Caporaso et al. 2010; J.G. Caporaso et al. 2012; J.G. Caporaso et al. 2011).

Figure 4. Second instar larvae at 38 days. The red arrow (at $2.3 \mathrm{~cm}$ ) indicated the point at which the abdomen was liberated from the thorax.

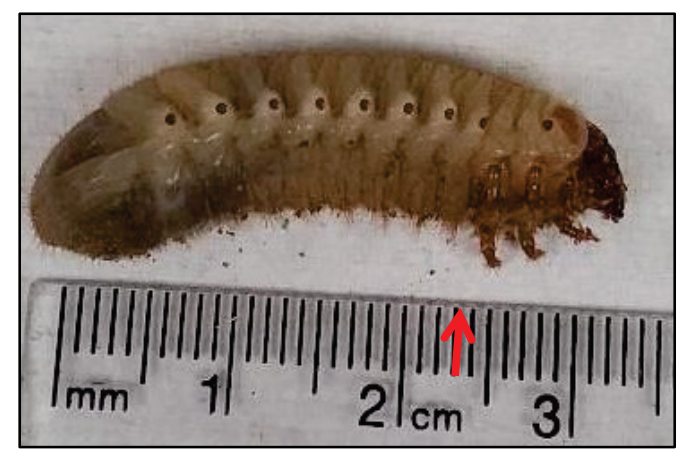

Briefly, DNA was extracted via a MoBio PowerSoil kit following the manufacturer's instructions, after which the resultant DNA was amplified with uniquely barcoded primers specifically designed for $16 \mathrm{~S}$ rRNA bacterial sequencing (515-806 bp region of the $16 \mathrm{~S}$ gene) (J.G. Caporaso et al. 2012) or ITS fungal sequencing (ITS1-ITS2 region, 230 bp) (https://www.earthmicrobiome.org/protocols-and-standards/its/). Amplicons were combined and normalized to $15 \mathrm{pmol}$ and further combined with 10\% PhiX control according to Illumina MiSeq instructions. Sequencing data was processed and analyzed using the QIIME (Quantitative Insights Into Microbial Ecology) bioinformatics pipeline (http://qiime.org/) for multivariate statistical analysis of sequencing data. Principal coordinates analysis (PCoA) was conducted using pairwise distances between bacterial communities (Bray-Curtis and UniFrac distances) to determine whether sample categories contained significantly different microbial communities. Relative abundances of bacterial community composition were assessed at the $2 \%$ abundance threshold, and significant differences in communities between samples were assessed with a Kruskal Wallis test incorporating a false discovery rate (FDR) $p$ value of 0.05. Alpha diversity was also assessed using QIIME. 


\section{Results and Discussion}

Mean weight of the laboratory-raised larvae (2019) at 112 days was $15 \%$ lower than the wild-caught larvae (2018), although this difference was not considered statistically significant (paired T-test; $p=0.09$ ) (figure 5). Also, at 112 days, the survival rate of larvae from laboratory-raised adults was $40 \%$ as compared to $70 \%$ for larvae from wild-caught adults. The sample time points between the two data sets do not match because of these samples being part of larger experiments. However, size measurements of laboratory-raised larvae would have been difficult beyond 112 days owing to massive attrition.

Figure 5. Body weight (solid lines) and survival (dashed lines) of larvae from wildcaught (2018, open symbols) and laboratory-raised (2019, solid symbols) adult beetles.

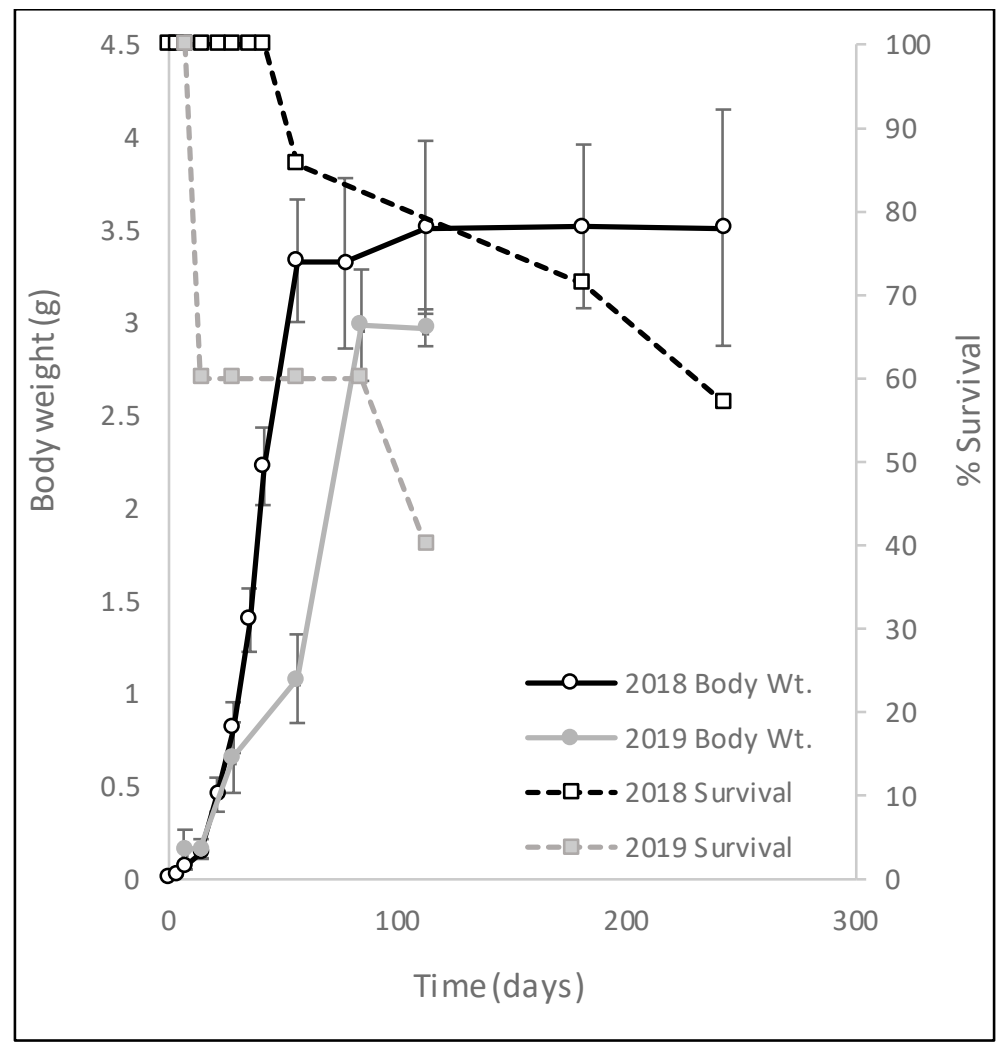

Numerous observations were made regarding behavioral and morphological differences in these two generations. First, laboratory-raised adult beetles (2019) did not appear robust, as they did not vigorously fly or feed like the wild-caught adults (2018). Also noteworthy was the lack of the expected alcohol odor from the growth chamber of the laboratory-raised adult beetles, which was abundantly present with the wild-caught adults. 
This difference indicated a lack of fermentative activity by the gut microbiome. Furthermore, upon death the legs and heads of the laboratory-raised beetles fell off the body-which never occurred with the wild-caught adults.

Comparisons of the bacterial microbiomes were conducted for the brood soil used by the adults and their larvae, gut extrusions from larvae and adults that were either wild caught (2018) or laboratory raised (2019), and fecal spurts from wild-caught adults (figure 6). The soil microbiomes were distinct from all beetle (adult or larvae) samples but similar to one another. This similarity was not unexpected, as the soil was mixed and used at the beginning of the entire effort and used for both generations of adults and larvae. For the adult gut microbial community profiling, several wildcaught adults from $2018(n=6)$ were eviscerated. The sex of each GJB was determined according to body length (males are smaller) and anterior tibial teeth (females have three, males have two) (Pszczolkowski, Hampton, and Johnson 2008). For the adult laboratory-raised GJBs adults $(n=3)$ included in gut microbial community profiling, GJBs were not sexed, as gender appeared to have no notable effect on microbiome communities. Additionally, as all laboratory-raised adults seemed less healthy, it was deemed that sex would have only a very slight impact on the microbiome compared to the substantial health decline. 
Figure 6. Phylogenetic survey at the family level of soil, adult and larvae gut microbiomes. The Enterococcaceae are denoted by the dark rose bars with italicized data labels and the Pseudomonadaceae by the dark green bars with underlined data labels.

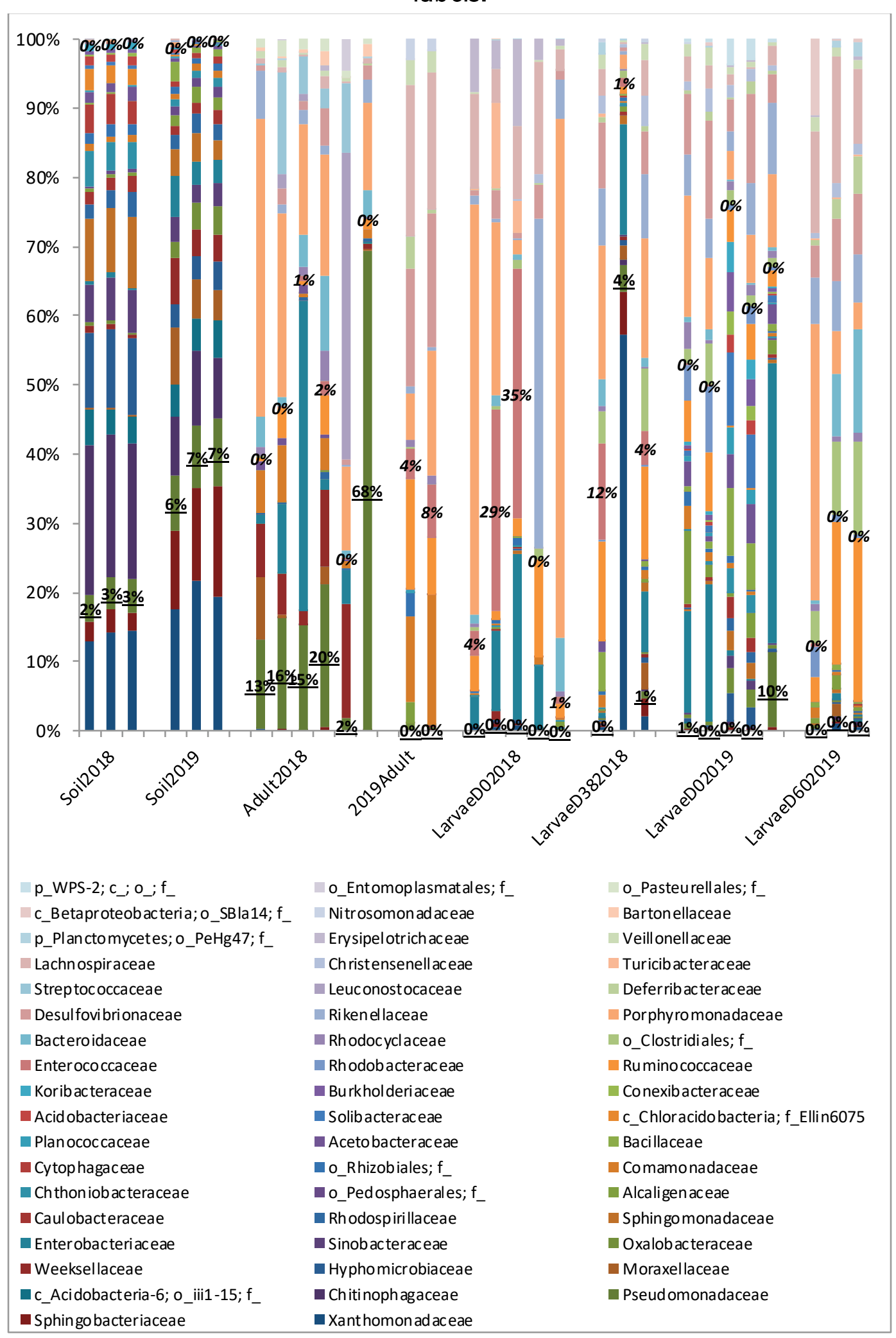


Numerous differences in gut microbial community profiles were observed from one generation to the next and between different developmental stages (figure 7; table 3). Wild-caught adults exhibited completely different profiles than laboratory-raised adults: most notable was the absence of Pseudomonadaceae in the laboratory-raised adults. The Pseudomonads are metabolically diverse and would potentially aid in the breakdown of numerous carbon and food sources in the gut. The laboratory-raised adults did not exhibit as large of a divergence in adult and larval gut microbial community profiles, as was observed with the wild-caught beetles. Also, the gut microbiomes of laboratory-raised adults and their larvae hosted large populations of Lachnospiraceae and Desulfovibrionaceae. These families were not observed in the wild-caught adults (table 3).

The difference in microbiome profiles between the wild-caught adults and their larvae (2018) was not unexpected. Efficient metabolism of simple sugars in adulthood and of complex plant polymers as larvae likely would necessitate a different gut microbiome community. The healthy early larval microbiome from the wild-caught adults contained all the expected gut organisms associated with insects that feed on carbonaceous plant polymers, such as Porphyromonadaceae, Rikenellacaea, Lachnospiraceae, Enterobacteraceae, and Enterococcaceae (Just et al. 2018; Liang et al. 2014). The second instar larval microbiome from the wild-caught adults looked similar to the first instar microbiome, with the exception of a decrease by about half in the Porphyromonadaceae in the second instar. The opposite trend was seen in the laboratory-raised larvae (table 3). The larvae hatched from laboratory-raised adults exhibited a disappearance of Enterococcaceae and a greater number of low-abundance families. This disappearance could indicate, just like the adults, that there is not pressure on the microbiome for specialized populations (eating and encountering mycorrhizal exudates, plant roots, animal feces) geared toward effective utilization of food input. The simple diet of alfalfa meal likely lacked critical nutrients and gut microbiome inocula, contributing to poor GJB health. 
Figure 7. Averaged phylogenetic survey at the family level of adult and larvae gut microbiomes. The Porphyromonadaceae are denoted by the light blue bars with white data labels, the Pseudomonadaceae by the royal blue bars with italicized white data labels, the Lachnospiraceae by the maroon bars with italicized black data labels, and the Desulfovibrionaceae by the orange bars with underlined black data labels.

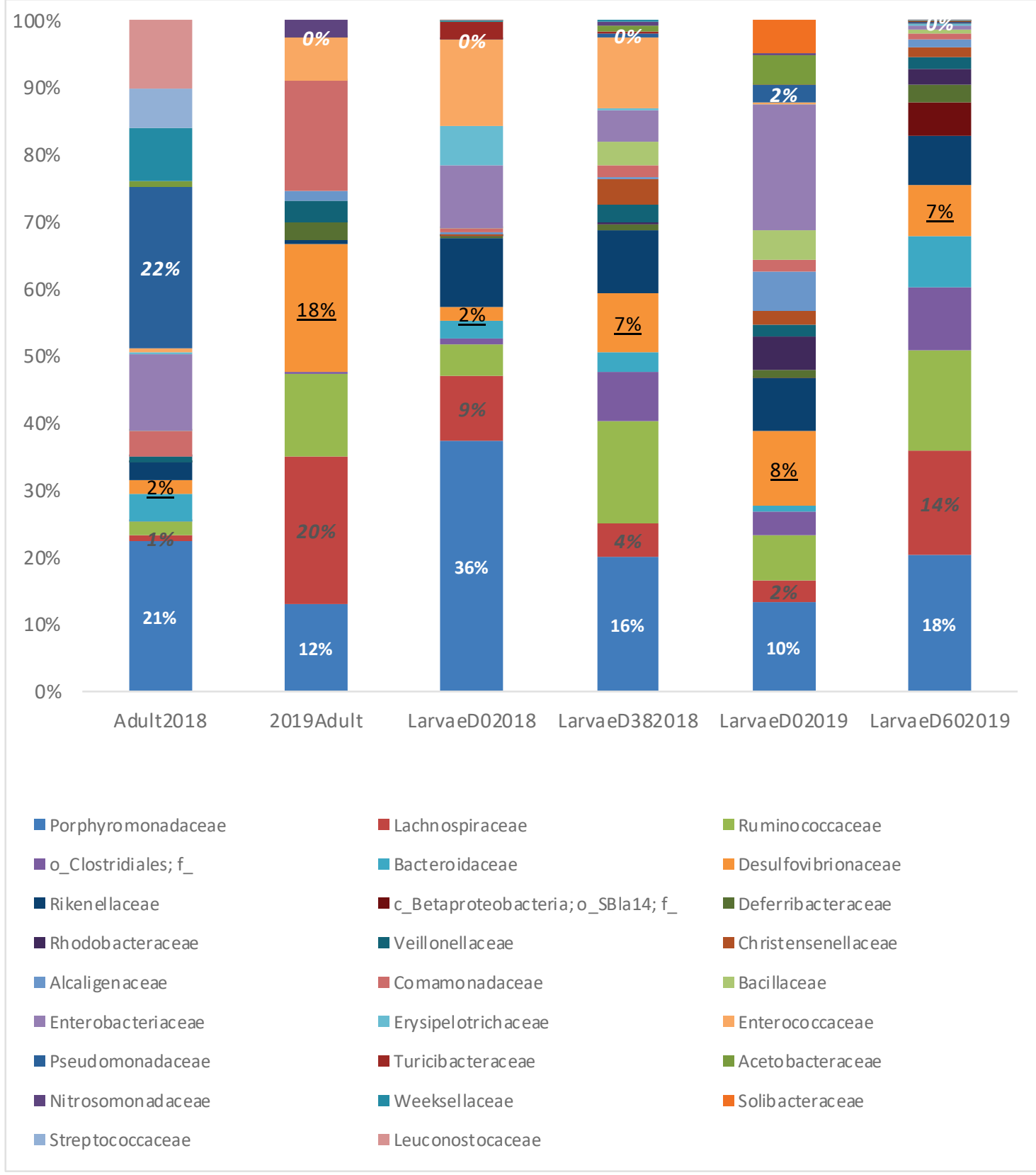


Table 3. Statistical summary of noteworthy population shifts from figure 7 using Kruskal-Wallis FDR $p$ values.

\begin{tabular}{|c|c|c|c|c|c|c|c|}
\hline Family & $\begin{array}{l}\text { FDR } \\
(p)\end{array}$ & $\begin{array}{l}\text { Adult } \\
2018\end{array}$ & $\begin{array}{l}\text { Adult } \\
2019\end{array}$ & $\begin{array}{l}\text { Larvae } \\
\text { D02018 }\end{array}$ & $\begin{array}{l}\text { Larvae } \\
\text { D38201 } \\
8\end{array}$ & $\begin{array}{l}\text { Larvae } \\
\text { D02019 }\end{array}$ & $\begin{array}{l}\text { Larvae } \\
\text { D602019 }\end{array}$ \\
\hline Lachnospiraceae & 0.019 & $1 \%$ & $20 \%$ & $10 \%$ & $3 \%$ & $2 \%$ & $13 \%$ \\
\hline $\begin{array}{l}\text { Pseudomonadace } \\
\text { ae }\end{array}$ & 0.019 & $22 \%$ & $0 \%$ & $0 \%$ & $2 \%$ & $2 \%$ & $0 \%$ \\
\hline Enterococcaceae & 0.049 & $1 \%$ & $6 \%$ & $14 \%$ & $6 \%$ & $0 \%$ & $0 \%$ \\
\hline $\begin{array}{l}\text { Desulfovibrionace } \\
\text { ae }\end{array}$ & 0.072 & $2 \%$ & $18 \%$ & $2 \%$ & $5 \%$ & $8 \%$ & $7 \%$ \\
\hline $\begin{array}{l}\text { Porphyromonadac } \\
\text { eae }\end{array}$ & 0.859 & $21 \%$ & $12 \%$ & $32 \%$ & $12 \%$ & $9 \%$ & $16 \%$ \\
\hline
\end{tabular}

Soil bacterial microbiome profiles were appreciatively different from the beetle microbiomes with a greater alpha diversity index (figure 8). Interestingly, the early larvae of the laboratory-raised GJB showed a higher gut microbial diversity than early larvae from the wild-caught GJBs. This increased diversity may indicate the lack of specialized populations in the laboratory-raised larvae, as discussed above. From an environmental microbiology perspective, a higher diversity generally means a healthier system, but in some cases specialization within the community, resulting in lower diversity, may be more beneficial. For example, lower diversity is not unusual where specialized or unique metabolisms or survival mechanisms are necessary, such as in extreme environments (Poli et al. 2017). 
Figure 8. Alpha-diversity plot (PD Whole tree) of the averaged bacterial populations of each sample type.

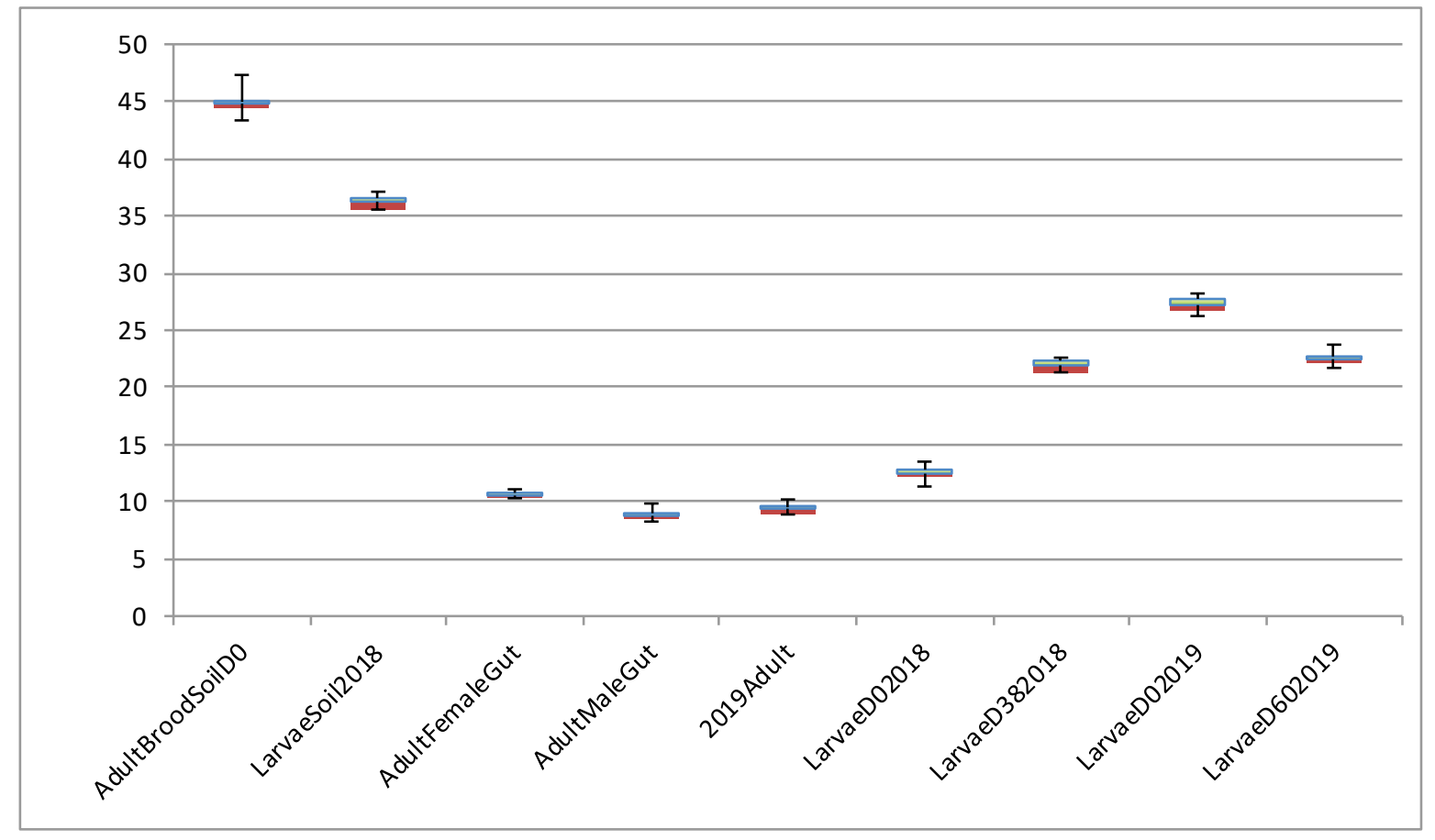

The results of the wild-caught beetle fungal microbiome survey (figure 9) supports early, culture-based work to discover important fungal gut populations in adults (D. Johnson 2009; Vishniac and Johnson 1990). These culture-based surveys found $>90 \%$ of the fungal biomass belonged to the order of fermentative yeasts, Saccharomycetales. Indeed, community sequencing using the ITS region with the 2018 wild-caught GJBs revealed $>80 \%$ of the total gut fungi were from the order Saccharomycetales, with much lower percentages from the fecal spurts. This order was not represented in either the soil or newly emerged larvae, indicating the food or fruit may have been the source of inocula. Five separate attempts to PCR amplify and sequence fungi from the larvae and adults of the 2019 laboratory-raised generation were unsuccessful. Although technically frustrating, a large-scale loss of fungi in the gut microbiome may be the most significant explanation for the general lack of health suspected in the laboratoryraised population. A simple remedy for this deficit may have been to feed adult GJBs fresh-picked fruit from the field, rather than store-bought organic fruit that have most certainly been washed. 
Figure 9. Fungal internal transcribed spacer (ITS) phylogenetic survey at the Order level for soil, adult and larvae gut microbiomes from wild-caught beetles at the start of experimentation. Light blue bars with data labels belong to the Saccharomycetales.

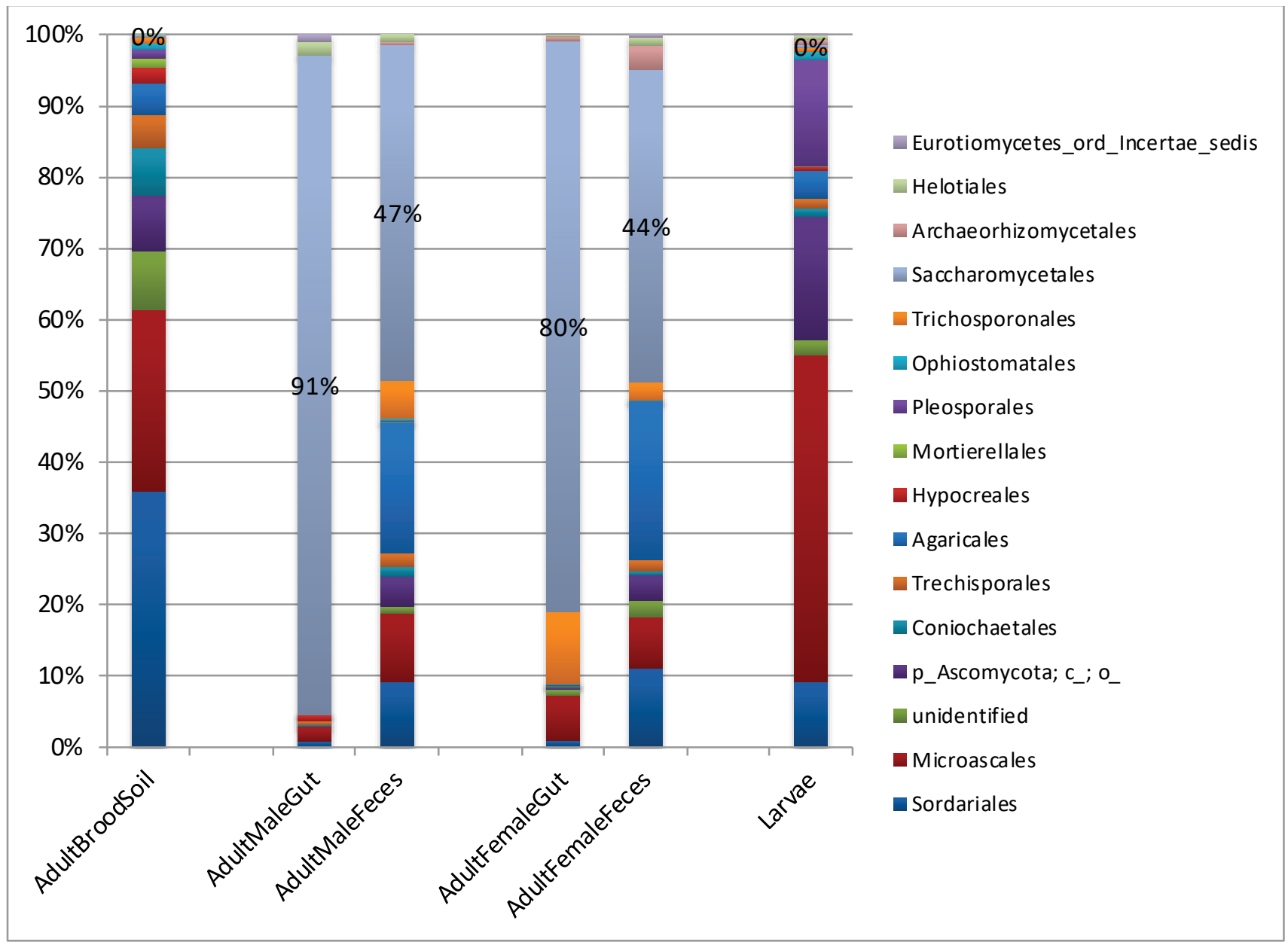




\section{Conclusion}

This study assessed the viability of the GJB as an invertebrate model animal for laboratory studies. Live-caught adult GJB were taken through an entire life cycle in a controlled laboratory environment and compared to laboratory-raised offspring. Health, survival, reproduction, and gut microbiome of both generations, and larvae and adult stages, were assessed.

GJBs are extremely easy to work with in all stages of development. Unfortunately, entirely laboratory-raised beetle adults appeared unhealthy; their eggs, although plentiful, were not as viable as wild-caught beetle eggs; and the larvae experienced high attrition. There were differences in the bacterial microbiomes of both the adult and larvae, as expected due to dietary shifts. However, there were also differences between the wild-caught and laboratory-raised adults and larvae. It was difficult to draw any conclusions from these data, other than to note there were community shifts. Most striking, however, was the near monoculture of fermentative yeasts in the wild-caught adult microbiome and the absence of this entire order of Saccharomyces from the larvae. There may have been a paucity of fungal biomass in the microbiome of these beetles. Previous research (Vishniac and Johnson 1990) and our sequencing of the brood soil (figures 6 and 9) indicate that the inoculation of the adult microbiome likely occurs not in the soil, but from the fruit eaten. Any attempts to repeat this experiment or rear GJBs over multiple generations may be far more successful if adults are fed organic, fresh-picked fruit that has not been washed. However, if just the larvae are needed for studies it may be beneficial to obtain freshly emerged, wild-caught adults and collect eggs from which larvae can be hatched. 


\section{References}

Caporaso, J. Gregory, Justin Kuczynski, Jesse Stombaugh, Kyle Bittinger, Frederic D Bushman, Elizabeth K Costello, Noah Fierer, et al. 2010. "QIIMEAllows Analysis of High-throughput Community Sequencing Data." Nature Methods 7, no. 5: 335-336. doi:10.1038/nmeth.f.303.

Caporaso, J. Gregory, Christian L. Lauber, William A. Walters, Donna Berg-Lyons, James Huntley, Noah Fierer, Sarah M. Owens, Jason Betley, Louise Fraser, Markus Bauer, Niall Gormley, Jack A. Gilbert, Geoff Smith and Rob Knight. 2012. "UltraHigh-throughput Microbial Community Analysis on the Illumina HiSeq and MiSeq Platforms." ISMEJournal 6:1621-1624.

Caporaso, J. Gregory, Christian L. Lauber, William A. Walters, Donna Berg Lyons, Catherine A. Lozupone, Peter J. Turnbaugh, Noah Fierer, and Rob Knight. 2011. "Global Patterns of 16S rRNA Diversity at a Depth of Millions of Sequences Per Sample." PNAS 108:4516-4522.

Estes, Anne M., David J. Hearn,Emilie C. Snell-Rood,Michele Feindler, Karla Feeser,Tselotie Abebe,Julie C. Dunning Hotopp,Armin P. Moczek. 2013. "Brood Ball-Mediated Transmission of Microbiome Members in the Dung Beetle, Onthophagus taurus (Coleoptera: Scarabaeidae)." PLoS ONE 8:e79061. doi:10.1371/journal.pone.0079061.

Howe, Wayne L., and William V. Campbell. 1953. "A Simple Method for Rearing Green June Beetle Larvae.” US Department of Agriculture, Agricultural Research Administration, Bureau of Entomology and Plant Quarantine. https://ufdc.ufl .edu/AAooo23217/00001.

Johnson, D. 2009. “Green June Beetles: The Wine Makers of The Insect World.” In Seminar, Department of Entomology, Penn State University, State College, Pennsylvania. PDF.

Johnson, D.T., B.A. Lewis, R.J. Bryant, R. Liyanage, J.O. Lay, M.A. Pszczolkowski. 2009."Attractants for the Green June Beetle (Coleoptera: Scarabaeidae)." Journal of Economic Entomology 102:2224-2232. doi:10.1603/029.102.0627.

Just Sarah, Stanislas Mondot, Josef Ecker, Katrin Wegner, Eva Rath, Laura Gau, Theresa Streidl, Genevieve Hery-Arnaud, Sinah Schmidt, Till Robin Lesker, Valentin Bieth, Andreas Dunkel, Till Strowig, Thomas Hofmann, DirkHaller, Gerhard Liebisch, Philippe Gérard, Sascha Rohn, Patricia Lepage and Thomas Clavel. 2018. "The Gut Microbiota Drives the Impact of Bile Acids and Fat Source in Diet On Mouse Metabolism." Microbiome 6. https://doi.org/10.1186/ s40168-018-0510-8.

Liang, Xue, Yuming Fu, Ling Tong and Hong Liu. 2014. "Microbial Shifts of the Silkworm Larval Gut in Response to Lettuce Leaf Feeding." Applied Microbiology and Biotechnology 98:3769-3776. https://doi.org/10.1007 /s00253-014-5532-y. 
Massart, Sébastien, Margarita Martinez-Medina, M. Haissam Jijakli. 2015. "Biological Control in the Microbiome Era: Challenges and Opportunities." Biological Control 89:98-108.https://doi.org/10.1016/j.biocontrol.2015.06.003.

Poli, Annarita, Ilaria Finore, Ida Romano, Alessia Gioiello, Licia Lama and Barbara Nicolaus. 2017. "Microbial Diversity in Extreme Marine Habitats and Their Biomolecules." Microorganisms 5, no. 2: 25. https://doi.org/10.3390 /microorganisms5020025.

Pszczolkowski, Maciej A, Kent Hampton, Dom Johnson. 2008. "Sexual Characteristics in a Midwestern USA Population of Cotinis nitida Linnaeus (Coleoptera: Scarabaeidae) and Consequences for Determining Gender.” The Coleopterists Bulletin 62, no. 4: 527-534. https://doi.org/10.1649/1105A.

Ptaszyńska, Aneta A., Grzegorz Borsuk, Agnieszka Zdybicka-Barabas, Małgorzata Cytryńska and Wanda Małek. 2016. "Are Commercial Probiotics and Prebiotics Effective in the Treatment and Prevention of Honeybee Nosemosis C?" Parasitology Research 115, no. 1: 397-406. doi:10.1007/so0436-015-4761-z.

Schwab, Daniel B., Hailey E. Riggs, Irene L. G. Newton, and Armin P. Moczek, and Natural History Editor: Mark A. McPeek. 2016. "Developmental and Ecological Benefits of the Maternally Transmitted Microbiota in a Dung Beetle." The American Naturalist 188, no. 6: 679-692. doi:10.1086/688926.

Shukla, Shantonu P., Jon G. Sanders, Marcus J. Byrne, Naomi E. Pierce. 2016. “Gut Microbiota of Dung Beetles Correspond to Dietary Specializations of Adults and Larvae." Molecular Ecology 25(24): 6092-6106. https://doi.org/10.1111/mec .13901 .

USEPA [US Environmental Protection Agency]. 2003.June Bugs Invade Links: Army Wins Battle, Loses War, Retreats, Finally Wins with New Tactics. EPA/903/F03/o05. Philadelphia, PA: EPA Region 3. https://permanent.fdlp.gov/lps36402 /junebugs.pdf.

Vishniac, H.S., and D.T. Johnson. 1990. "Development of a YeastfFora in the Adult Green June Beetle (Cotinis nitida, Scarabaeidae).” Mycologia 82:471-479. 


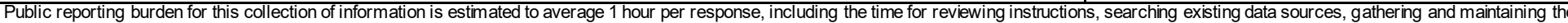

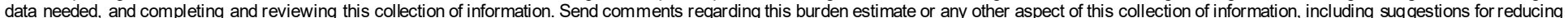

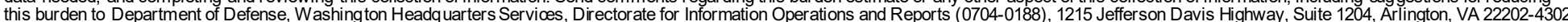

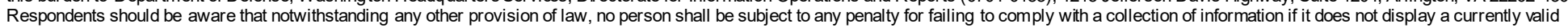
OMB control number. PLEASE DO NOT RETURN YOUR FORM TO THE ABOVE ADDRESS.

\begin{tabular}{|l|l|l}
\hline 1. REPORT DATE & 2. REPORT TYPE & 3. DATES COVERED (From - To)
\end{tabular}

\section{TITLE AND SUBTITLE}

Final

Microbiome Perturbations During Domestication of the Green June Beetle (Cotinis nitida) 5a. CONTRACT NUMBER

\section{AUTHOR(S)}

Carina M. Jung, Matthew Carr, Denise L. Lindsay, Eric Fleischman, and Chandler J. Roesch

\section{5b. GRANT NUMBER}

5c. PROGRAM ELEMENT NUMBER

611102AB2

5d. PROJECT NUMBER

484234

5e. TASK NUMBER

A1170

5f. WORK UNIT NUMBER

7. PERFORMING ORGANIZATION NAME(S) AND ADDRESS(ES)

U.S. Army Engineer Research and Development Center

Environmental La boratory

3909 Halls Ferry Road

8. PERFORMING ORGANIZATION REPORT NUMBER

Vicksburg, MS 39180

ERDC/EL TR-22-1

\section{SPONSORING / MONITORING AGENCY NAME(S) AND ADDRESS(ES)}

US Army Corps of Engineers

Wa shington, DC 20314

\section{USACE}

11. SPONSOR/MONITOR'S REPORT NUMBER(S)

\section{DISTRIBUTION / AVAILABILITY STATEMENT}

Approved for public release; distribution is unlimited.

\section{SUPPLEMENTARY NOTES}

Funding provided underEQI Military Direct 6.1 Basic Research Program.

\section{ABSTRACT}

Animal-associated microbiomes are critical to the well-being and proper functioning of the a nimal host, but only limited studies have examined insect microbiomes a cross different developmental stages. These studies revealed large shifts in microbiomecommunities, often beca use of signif-icant shifts in diet during in sects' life cycle. Establishing insect colonies as model la boratory organisms and understanding how to properly feed and care for a nimals with complex and dynamic life cycles requires im-proved data. This study examined la boratory-raised green June beetles (Cotinis nitida) captured from the field upon emergence from pupae. Starting with wildcaught a dults, two generations of beetles were reared in the laboratory, ending with an entirely laboratory-raised generation of larvae. The study compared the microbiomes of each generation and the microbiomes oflarvae to adults. This study suggests that a diet of commercial, wa shed fruit for a dults and commercial, pa ckaged, orga nic alfal-fa meal for la rvae resulted in depauperate gut microbiome communities. Fermentative yeasts were completely absent in the laboratory-raised a dults, a nd major bacteria l population shifts occurred from one genera-tion to the next, coupled with high morbidity and mortality in the la bora-tory-raised generation. Providing laboratoryraised beetles fresh-collected fruit and the la rvae field-harvested detritus may therefore vast-ly improve their health a nd survival.

\section{SUBJECT TERMS}

Green June beetle

Laboratory organisms

Insects - Food

\section{SECURITY CLASSIFICATION OF:}

a. REPORT Unclassified

\section{b. ABSTRACT} Unclassified c. THIS PAGE

Uncla ssified
17. LIMITATION
OF ABSTRACT

UU

\begin{tabular}{l|l}
$\begin{array}{l}\text { 18. NUMBER } \\
\text { OF PAGES } \\
27\end{array}$ & \\
\cline { 2 - 2 } &
\end{tabular}

19a. NAME OF RESPONSIBLE PERSON

19b. TELEPHONE NUMBER 